\section{Stratification Improves Seed Germination of Five Native Wildflower Species}

\author{
Carlma B. Bratcher ${ }^{1}$, John M. Dole ${ }^{2}$, and Janet C. Cole ${ }^{2}$ \\ Department of Horticulture and Landscape Architecture, Oklahoma State \\ University, Stillwater, OK 74078-0511
}

Additional index words. Baptisia australis, Echinacea purpurea, Helianthus maximiliani, seed dormancy, Solidago petiolaris, Vernonia missurica

\begin{abstract}
The germination responses of wild blue indigo [Baptisia australis (L.) R. Br.], purple coneflower [Echinacea purpurea (L.) Moench.], Maximilian sunflower (Helianthus maximiliani Schrad.), spike goldenrod (Solidago petiolaris Ait.), and Missouri ironweed (Vernonia missurica Raf.) seeds after $0,2,4,6,8$, or 10 weeks of stratification at $5 \mathrm{C}$ were investigated. Seed viability was determined using triphenyl tetrazolium chloride staining and germination based on the percentage of viable seeds. Germination percentage (GP) increased in all five species as weeks of stratification increased. Days to first germination and germination range (days from first to last germinating seed) decreased with increasing weeks of stratification, but the effect beyond 4 to 6 weeks was minimal. The number of weeks of stratification for maximum GP was 4 for purple coneflower, 6 for Maximilian sunflower, 8 for Missouri ironweed, and 10 for wild blue indigo and spike goldenrod.
\end{abstract}

Interest in using native wildflowers as low-maintenance ornamentals and landscape plantings and for prairie preservation has increased (Cox and Klett, 1984; Salac et al., 1982). Wildflowers may be suited for cutflower production in Oklahoma because of their adaptation to the local environment and low maintenance and water requirements. Preliminary work identified five species with potential for use as cut flowers in the United States-wild blue indigo, purple coneflower, Maximilian sunflower, spike goldenrod, and Missouri ironweed (Bratcher, 1992). Some criteria for selecting possible wildflowers included rapid, uniform germination and establishment; resistance or tolerance to insect and disease damage; attractive flower color; strong stems of sufficient length for cut flowers; and a long postharvest flower life.

Dormancy ensures that seeds do not germinate in temperate climates until conditions are optimal for seedling survival (Bewley and Black, 1982). Seeds of many species require stratification-a moist, cold storage periodto overcome dormancy. The physiological dormancy and propagation requirements associated with many wildflowers discourages growers. While the mechanisms of dormancy and conditions for maximum seed germina-

\footnotetext{
Received for publication 23 Dec. 1992. Accepted for publication 14 May 1993. Oklahoma Agricultural Experiment Station Journal article no. 6316. This research was supported in part by the Oklahoma Center for the Advancement of Science and Technology. The cost of publishing this paper was defrayed in part by the payment of page charges. Under postal regulations, this paper therefore must be hereby marked advertisement solely to indicate this fact.

${ }^{1}$ Former Graduate Research Assistant. ${ }^{2}$ Assistant Professor.
}

tion are unknown for many wildflowers, some species have been studied (Allen and Meyer, 1990; Kitchen and Meyer, 1991; Salac and Hesse, 1975). Storage conditions and germination requirements were evaluated for Liatris aspera Michx., Liatris pycnostachya Michx., Asclepias tuberosa L., and Penstemon grandiflorus Nutt. (Salac and Hesse, 1975). Optimal seed germination of all of these species occurred after seeds were stratified at $4 \mathrm{C}$. Two weeks of stratification did not break seed dormancy of Penstemon palmeri Gray or Penstemon eatonii Gray, but 8 weeks of stratification did (Allen and Meyer, 1990). Also, optimal germination occurred at $15 \mathrm{C}$, and incubation at $>2 \mathrm{OC}$ decreased germination for both Penstemon species.

The greatest emergence of purple coneflower seeds was obtained by planting in November, and that of Maximilian sunflower was obtained with November and April outdoor seedings in Nebraska (Salac et al., 1982). Possibly, Maximilian sunflower had either no dormancy or a limited dormancy requirement. Purple coneflower germination rate was highest when seeds were placed in moist sand or peat at $0 \mathrm{C}$ for 1 month (Smith-Jochum and Albrecht, 1987).

The objective of this study was to determine the stratification duration that would maximize germination percentage (GP) and minimize the days to first germination (FG) and the germination range (GR) (days from first to last seed germination) for seeds of five wildflower species.

Spike goldenrod and Missouri ironweed seeds were collected in Stillwater, Okla., in Fall 1990, and purple coneflower (Park Seed Co., Greenwood, S.C.), wild blue indigo (Germania Seed Co., Chicago), and Maximilian sunflower (Plants of the Southwest, Santa Fe, N.M.) seeds were obtained from producers at the same time. The seeds were stored at $20 \pm 4 \mathrm{C}$ until beginning the stratification treatments on 15 June 1991.

Four SO-seed replications were soaked in distilled water in darkness for $12 \mathrm{~h}$. Each seed was pierced with a needle to allow water absorption.. The seeds were placed in 9-cmdiameter plastic petri dishes lined with P8-creped filter paper (Fisher Scientific, Pittsburgh) and containing $10 \mathrm{ml} 0.1 \%(\mathrm{w} / \mathrm{v})$ triphenyl tetrazolium chloride (TTC) solution. After $48 \mathrm{~h}$, the seeds were bisected under a dissecting microscope. Only embryos stained red were considered viable (Allen and Meyer, 1990).

Seeds of all five species were subjected to six treatments: $20 \pm 3 \mathrm{C}$ (no stratification) or stratification at $5 \pm 2 \mathrm{C}$ for $2,4,6,8$, or 10 weeks. For each treatment, four 50-seed replications of all species, except wild blue indigo (10 seeds/replication), were placed randomly in filter paper-lined, covered petri dishes and moistened with distilled water as needed. Petri dishes were placed in darkness at 5C for the duration of each stratification treatment. On completion of each treatment, seeds were placed at $20 \pm 3 \mathrm{C}$ under natural light and daylengths (lat. $36^{\circ} 07^{\prime} \mathrm{N}$ ) $1 \mathrm{~m}$ from a laboratory window. The experiment was repeated in 1992 for wild blue indigo with the same materials and methods as used in the first year, with 18 seeds/replication.

The number of germinated seeds (radicle $\geq 1 \mathrm{~mm}$ long) was recorded daily. GP was based on the percentage of viable seeds for each species. For example, if viability was $50 \%$ and 25 of 50 seeds planted germinated, then GP was $100 \%$. Data were analyzed using trend analysis (SAS Institute, Cary, N.C.).

Wild blue indigo. Results for both years were similar; thus, we report only 1992 results. GPs of seeds given 2 and 4 weeks of stratification were significantly lower than those of seeds that received no stratification. However, GP steadily increased after 24 weeks of stratification (Fig. 1A). Possibly, the seeds developed secondary dormancy on initial exposure to the low temperature and continued stratification overcame this dormancy (Bewley and Black, 1982). The highest GP was obtained after 10 weeks of stratification. Both GP and FG were affected quadratically by length of stratification, while GR decreased linearly (Table 1). Using the TTC staining technique, viability was $67.5 \%$ ( $\mathrm{SE}=7.14$ ).

Purple coneflower. GP was highest after 4 weeks of stratification and declined with longer stratification (Fig. 1B). GP was quadratic, GR linear, and FG cubic in response to stratification duration (Table 1). Using the TTC staining technique, viability was $93.5 \%$ ( $\mathrm{SE}=\mathbf{1} \mathbf{. 0 4})$. Optimal germination occurred after 4 weeks of stratification, a result in agreement with Smith-Jochum and Albrecht (1987), who found increased purple coneflower germination after seeds were exposed to $0 \mathrm{C}$ for 1 month.

Maximilian sunflower. The highest GP occurred after 6 to 10 weeks of stratification, a response that was cubic (Fig. 1C, Table 1). GR decreased linearly, and FG was a cubic response. Maximilian sunflower reached $98 \%$ 


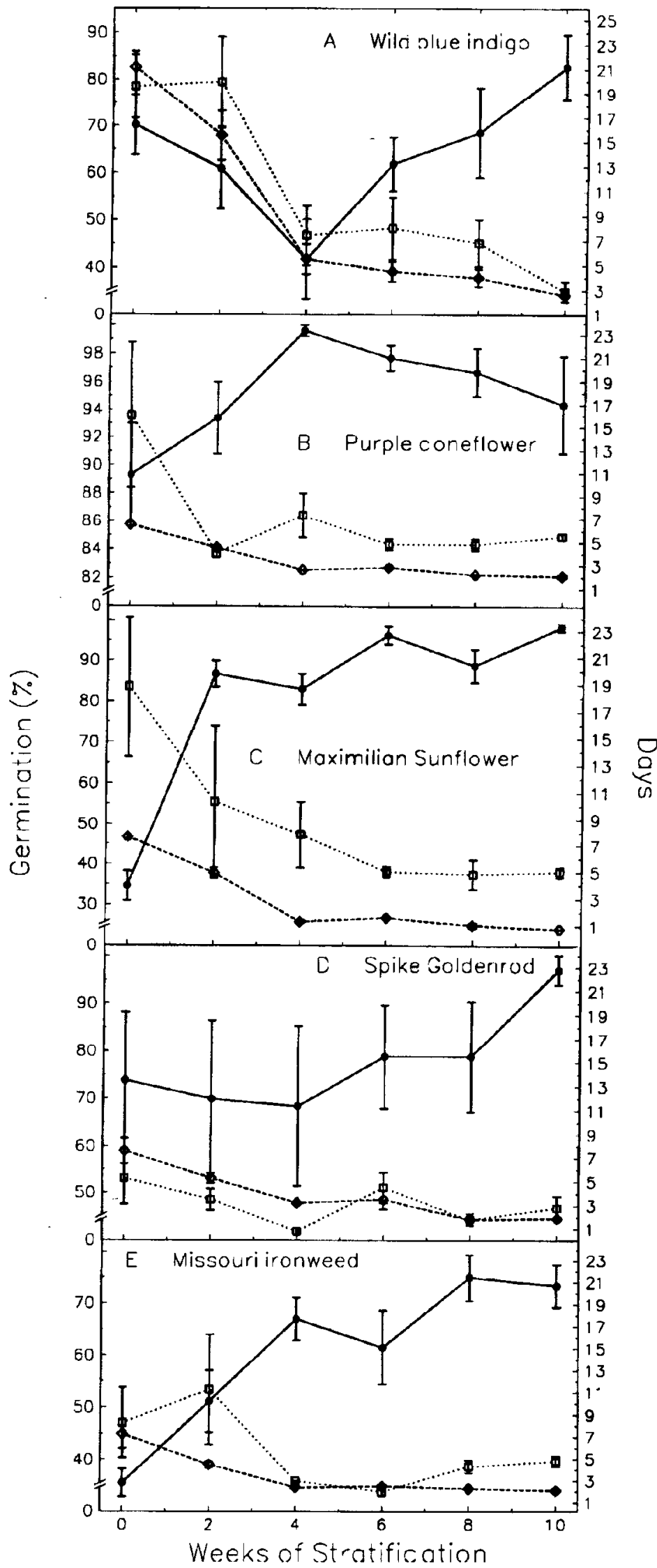

Fig. 1. Germination percentage (GP) (based on percentage of viable seeds) ( $)$, germination range (days from first to last germinated seed) (D), and days to first germination $(\boldsymbol{O})$ for $(\mathbf{A})$ wild blue indigo, $(\mathbf{B})$ purple coneflower, (C) Maximilian sunflower, (D) spike goldenrod, and (E) Missouri ironweed after 0 , $2,4,6,8$, or 10 weeks of $5 \mathrm{C}$ stratification. Vertical bars represent $\pm \mathrm{SE}$; bars smaller than symbols are not shown. Scales for GPs differ among species. of total germination with a 6-day GR after 6 weeks of stratification (Table 1, Fig. 1C). Although a longer exposure to cold raised GP to $100 \%$ of viable seeds, the GR remained constant. Also, after 6 weeks at $5 \mathrm{C}$, seeds already had germinated in the cooler. Viability was $94 \%$ ( SE = 2.35).

Spike goldenrod. GP was highest after 10 weeks of stratification (Fig. 1D). FG responded quadratically, but GR failed to respond to weeks of stratification (Table 1). Optimal germination occurred after 10 weeks of stratification. Viability was $20.5 \%$ ( $\mathbf{S E}=\mathbf{3 . 0 7}$ ).

Missouri ironweed. GP was highest after 8 to 10 weeks of stratification (Fig. 1E). GP and GR responded linearly and FG quadratically to weeks of stratification (Table 1). Optimal germination occurred with 10 weeks of stratification. Viability was $63.5 \%$ ( SE $=3.75$ ). Missouri ironweed seeds did not germinate to their full potential based on the calculated viability. However, viability refers to seeds that have the potential to germinate. Other viable seeds may not have germinated due to their possible need for further stratification (Bewley and Black, 1982).

Failure of a seed to germinate when placed in the correct environment (water, oxygen, temperature) indicates seed dormancy. Seed dormancy optimizes the distribution of germination over time and prevents germination when physical factors such as light and temperature could affect seedling survival adversely (Bewley and Black, 1982). Two types of dormancy found in seeds are endodormancy and paradormancy. Endodormancy (physiological or embryo dormancy) is due to internal physiological factors. Stratification breaks physiological dormancy, but the fundamental control process is not yet known. Paradormancy (physical dormancy or coat-imposed dormancy) is due to the enclosing structures surrounding the embryo.

While seeds of all of the wildflower species responded positively to stratification-a result indicating endodormancy- neither wild blue indigo nor Missouri ironweed seeds germinated to their full potential based on the viability percentage calculated from the TTC test (Fig. $1 \mathrm{~A}$ and E). These species possibly went into secondary endodormancy, which may have been overcome by further exposure to cold (Bewley and Black, 1982). Also, since wild blue indigo has a hard seedcoat (paradormancy), scarification before stratification might have increased seed germination (Atwater, 1980; Phillips, 1985). However, the additional effort and risk to the seed from scarification may not be needed, considering that the maximum GP for wild blue indigo was already $83 \%$ with 10 weeks of stratification. Stratification decreased FG and GR in all species, but the effect was minimal after 6 weeks. After 4 to 6 weeks of stratification, both FG and GR were at acceptable levels and a further decrease was not essential for optima1 germination. After stratification, all viable seeds of purple coneflower, Maximilian sunflower, and spike goldenrod had germinated in 4, 6, and 10 weeks, respectively. 
Table 1. F test significance for trend analysis on the effect of temperature on germination percentage (GP), germination range (GR) (days from first to last germinated seed), and days to first germination (FG) of five native wildflowers after $0,2,4,6,8$, or 10 weeks of stratification at $5 \mathrm{C}$.

\begin{tabular}{|c|c|c|c|}
\hline \multirow[b]{2}{*}{ Criterion } & \multicolumn{3}{|c|}{$\mathrm{F}$ test probability and $\mathrm{SS}^{\mathrm{z}}(\%)$} \\
\hline & GP & GR & FG \\
\hline \multicolumn{4}{|c|}{ Wild blue indigo } \\
\hline Linear & Ns $(3.3)$ & $*(20.7)$ & $* * *(39.0)$ \\
\hline Quadratic & $* *(35.6)$ & NS $(6.5)$ & $*(17.4)$ \\
\hline Cubic & Ns (3.5) & NS $(0.0)$ & Ns $(0.0)$ \\
\hline \multicolumn{4}{|c|}{ Purple coneflower } \\
\hline Linear & NS (8.9) & $*(17.0)$ & $* * *(77.7)$ \\
\hline Quadratic & $*(25.0)$ & NS $(13.1)$ & $* * *(15.7)$ \\
\hline Cubic & NS $(0.3)$ & NS $(5.4)$ & $* *(1.4)$ \\
\hline \multicolumn{4}{|c|}{ Maximilian sunflower } \\
\hline Linear & $* * *(55.2)$ & $* *(32.1)$ & $* * *(75.6)$ \\
\hline Quadratic & $* * *(20.8)$ & NS $(9.6)$ & $* * *(17.9)$ \\
\hline Cubic & $* * *(11.8)$ & NS $(0.6)$ & $*(0.9)$ \\
\hline \multicolumn{4}{|c|}{ Spike goldenrod } \\
\hline Linear & NS $(9.2)$ & NS (7.1) & $* * *(71.8)$ \\
\hline Quadratic & NS (4.4) & Ns $(5.7)$ & $*(7.4)$ \\
\hline Cubic & NS $(0.0)$ & NS (3.3) & NS $(0.6)$ \\
\hline Linear & \multicolumn{3}{|c|}{ Missouri ironweed } \\
\hline Quadratic & NS $(7.0)$ & NS (6.1) & $* * *(19.3)$ \\
\hline Cubic & NS $(0.7)$ & NS $(4.2)$ & NS $(0.2)$ \\
\hline
\end{tabular}

${ }^{\mathrm{z} S S}=$ sums of squares; contribution of each trend component to the total SS of the model.

${ }^{\mathrm{Ns},{ }^{*}, * *, * * *}$ Nonsignificant or significant at $P \leq 0.05,0.01$, or 0.001 , respectively.

\section{Literature Cited}

Allen, P.S. and S.E. Meyer. 1990. Temperature requirements for seed germination of three Penstemon species. HortScience 25:191-193.

Atwater, B.R. 1980. Germination, dormancy and morphology of the seeds of herbaceous ornamental plants. Seed Sci. \& Technol. 8:523-573.

Bewley, J.D. and M. Black. 1982. Physiology and biochemistry of seeds in relation to germination. II. Viability, dormancy, andenvironmental control. Springer-Verlag, Berlin.

Bratcher, C.B. 1992. Methods of producing field-grown specialty cut flowers. MS Thesis, Oklahoma State Univ., Stillwater.

Cox, R.A. and J.E. Klett. 1984. Seed germination requirements of native Colorado plants for use in the landscape. Plant Prop. 30:359-361.

Kitchen, S.G. and S.E. Meyer. 1991. Seed germination of intermountain penstemons as influenced by stratification and GA, treatments. J. Environ. Hort. 9:51-56.

Phillips, H.R. 1985. Growing and propagating wildflowers. Univ. of North Carolina Press, Chapel Hill.

Salac, S.S. and M.C. Hesse. 1975. Effects of storage and germination conditions on the germination of four species of wildflowers. J. Amer. Soc. Hort. Sci. 100:359-361.

Salac, S.S., J.M. Traeger, and P.N. Jenson. 1982. Seeding dates and field establishment of wildflowers. HortScience 17:805-806.

Smith-Jochum, C.C. and M.L. Albrecht. 1987. Field establishment of three Echinacea species for commercial production. Acta Hort. 208:115118 . 